Research Paper

\title{
Synergistic action of an Aspergillus (hemi-)cellulolytic consortium on sugarcane bagasse saccharification
}

\author{
Patrísia de Oliveira Rodrigues $^{\mathrm{a}}$, Josiani de Cássia Pereira ${ }^{\mathrm{b}}$, Douglas Queiroz Santos ${ }^{\mathrm{c}}$, \\ Leandro Vinícius Alves Gurgel ${ }^{\mathrm{d}}$, Daniel Pasquini ${ }^{\mathrm{e}}$, Milla Alves Baffi ${ }^{\mathrm{a}, *}$ \\ a Institute of Agricultural Sciences, Federal University of Uberlândia (ICIAG-UFU), 38405-320 Uberlândia, Minas Gerais, Brazil \\ ${ }^{\mathrm{b}}$ Institute of Biosciences, Humanities and Exact Sciences, São Paulo State University (IBILCE-UNESP), 15054-000 São Jose do Rio Preto, São Paulo, Brazil \\ c Technical School of Health, Federal University of Uberlândia (ESTES-UFU), 38400-902 Uberlândia, Minas Gerais, Brazil \\ ${ }^{\mathrm{d}}$ Institute of Exact and Biological Sciences, Federal University of Ouro Preto (ICEB-UFOP), 35400-000 Ouro Preto, Minas Gerais, Brazil \\ ${ }^{\mathrm{e}}$ Institute of Chemistry, Federal University of Uberlândia (IQ-UFU), 38400-902 Uberlândia, Minas Gerais, Brazil
}

\section{A R T I C L E I N F O}

\section{Keywords:}

Aspergillus fumigatus

Aspergillus niger

Enzymatic hydrolysis

Sugarcane bagasse

Alkaline pretreatment

Second-generation ethanol

\begin{abstract}
A B S T R A C T
This study evaluated the synergistic efficiency of crude enzymatic extracts (CEE) produced by fungal strains Aspergillus fumigatus SCBM6 (AFE) and Aspergillus niger SCBM1 (ANE) in the hydrolysis of alkali pretreated sugarcane bagasse $\left(2 \% \mathrm{NaOH}\left(\mathrm{w} \mathrm{v}^{-1}\right), \sim 100^{\circ} \mathrm{C}, 4 \mathrm{~h}\right.$ and liquid-to-solid ratio of $\left.25\left(\mathrm{v} \mathrm{w}^{-1}\right)\right)$. CEEs were produced by solid-state fermentation (SSF) and presented high concentration of $\beta$-glucosidase (AFE $=78.4 \mathrm{Ug}^{-1}$ and $\left.\quad \mathrm{ANE}=43.02 \mathrm{Ug}^{-1}\right), \quad \beta$-xylosidase $\quad\left(\mathrm{ANE}=78.0 \mathrm{Ug}^{-1}\right) \quad$ and $x y l a n a s e \quad\left(\mathrm{AFE}=1774.5 \mathrm{Ug}^{-1}\right.$ and ANE $=3289.6 \mathrm{U} \mathrm{g}^{-1}$ ). A $2^{4}$ full design of experiments was used to optimize the hydrolysis of pretreated bagasse as a function of time, temperature, amount of pretreated bagasse and AFE-to-ANE ratio. After hydrolysis optimization, the maximum concentration of total reducing sugars (TRS) was $21.68 \mathrm{~g} \mathrm{~L}^{-1}$. It was also noticed a significant production of xylose $(135.59 \mathrm{mg})$ and arabinose $(58.10 \mathrm{mg})$ per gram of hemicelluloses and a slight production of glucose $(20.18 \mathrm{mg})$ per gram of cellulose. As fungi consortium were excellent producers of hemicellulases, it is suggested that they could be used for pentoses saccharification and production of ethanol via C-5 fermentation, xylitol, biopolymers, among other bioproducts.
\end{abstract}

\section{Introduction}

The indiscriminate use of fossil fuels, the instability in the oil market and environmental pollution have contributed to the search for alternative and less-pollutant energy sources. In this context, agroindustrial by-products constitute biomasses with a vast potential for use in the production of biofuels and value-added bioproducts. Among the largest agroindustrial by-products in the world is sugarcane bagasse (SCB). Thus, the use of SCB for bioenergy production can then contribute to the energy matrix and reduce environmental problems associated with deforestation, increase of planting areas and the accumulation of this residue into the environment (Baêta et al., 2016; Liu et al., 2017a).

Sugarcane is cultivated throughout the world. Brazil is the main producer, followed by India and China (CONAB, 2017). In Brazil, the sugarcane production from the $2017 / 2018$ harvest was estimated in 647.6 million tons, generating about 140 million tons of SCB (CONAB, 2017). SCB is a lignocellulose residue composed by cellulose (30-45\%), hemicelluloses (25-30\%) and lignin (25-30\%), whose the polysaccharide fraction can be converted into fermentable monosaccharides for the production of second-generation ethanol (2G ethanol) (Badshah et al., 2012). However, the interaction among these three major components in the plant cell wall makes the lignocellulose biomass rigid, complex and recalcitrant, thereby requiring one or more pretreatment for improving the accessibility to the enzymes during the saccharification step (Brienzo et al., 2017).

For the use of SCB in the production of $2 \mathrm{G}$ ethanol, it is required the decrease of the recalcitrance of biomass and depolymerization of polysaccharides with consequent release of monosaccharides, which can be accomplished through three stages, i.e. pretreatment (physical, chemical or biological), enzymatic hydrolysis and fermentation (Karp et al., 2013). The pretreatment step aims to reduce the protective association of lignin and represents the major challenge in the use of biomass for $2 \mathrm{G}$ ethanol production. This step removes part of lignin and does not change the crystallinity of cellulose (Dougherty et al., 2014; Liu et al., 2017b), thereby decreasing the recalcitrance of biomass, and therefore, facilitating the next step of enzymatic hydrolysis (Chandra et al., 2012; Karp et al., 2013; Rodrigues et al., 2017).

\footnotetext{
* Corresponding author.

E-mail addresses: millabaffi@yahoo.com.br, milla.baffi@ufu.br (M.A. Baffi).
} 
The alkaline pretreatment (APT) directly acts in the biomass structure, promoting the delignification of biomass through the cleavage of $\alpha$ - and $\beta$-alkyl- and aryl-ether bonds and deprotonating the released phenolic groups of lignin, depolymerizing the cellulose (Oliveira et al., 2014), removing the acetyl groups and part of uronic acids of the xylan chain, thereby increasing the susceptibility of the substrate to enzymatic hydrolysis (Kumar et al., 2009). In addition, it can be operated at low temperatures and even under atmospheric pressure (Mood et al., 2013), and the chemicals used in this pretreatment cause lower corrosion of the equipment in comparison to the acidcatalyzed pretreatments (Modenbach and Nokes, 2012). Another advantage is the increase of the porosity of the biomass due to the lignin removal (Chandra et al., 2012). As a drawback, this pretreatment has the cost of the chemicals and the requirement of an additional step for the recovery of the chemicals for a new cycle in a similar way that has been made in the cellulose and paper industry (Pallapolu et al., 2011). However, a recent study based on life-cycle analysis of the $2 \mathrm{G}$ ethanol production process using APT as the only pretreatment step showed that sodium hydroxide can be recovered and reused, thereby contributing to the process become economically feasible (Rocha et al., 2014).

In recent years, studies involving enzymatic catalytic conversion of lignocellulose biomass have become the target of various researches worldwide (Canilha et al., 2012; Pereira et al., 2016). On the other hand, the use of enzymes in the hydrolysis step has an elevated cost when it comes to the use of commercial cocktails. In order to solve this challenge, it is important to search for efficient and economically viable enzyme-producing microorganisms (Moretti et al., 2012; Santos et al., 2015). The hydrolytic enzymes are mainly produced by filamentous fungi and several studies have been performed to select strains with a high rate of enzyme production, especially hemicellulases and cellulases (Boonyuen et al., 2014; Santos et al., 2015). Among the cellulases, $\beta$-glucosidases or cellobiases (EC 3.2.1.21) have the function of ending the hydrolysis of cellulose, releasing glucose from cellobioses and cellooligosaccharides previously generated by the action of other enzymes of the cellulolytic complex, which are fundamental for the success of the saccharification process (Murphy et al., 2013; Watanabe and Tokuda, 2010). Therefore, an efficient hydrolysis depends on the right proportion among these enzymes.

Experiments using enzymatic consortium from fungi demonstrated a greater production of cellulases and efficiency on saccharification compared to the performance of an enzymatic extract from a single microorganism (Zhang et al., 2009). Recent studies using cellulases/ hemicellulases mixtures from different fungal species have been developed in order to increase the enzymatic potential on the saccharification, mainly from Trichoderma reesei and Penicillium chrysosporium (Khajeeram and Unrean, 2017; Lin et al., 2011).

This study aimed to evaluate the synergistic efficiency of a newly developed (hemi)-cellulolytic consortium produced by the fungal strains Aspergillus fumigatus SCBM6 and Aspergillus niger SCBM1 in the enzymatic hydrolysis of alkali pretreated SCB. To the best of our knowledge, this is the first report on the use of Aspergillus enzymatic mixtures on SCB hydrolysis using low cost methodologies. The enzymatic hydrolysis process was optimized by a $2^{4}$ full design of experiments and the independent variables evaluated were temperature, time, amount pretreated SCB and AFE-to-ANE ratio.

\section{Material and methods}

\subsection{Chemicals}

Sodium hydroxide, potassium tartrate, ammonium sulfate, calcium chloride and sodium carbonate were purchase from Dinâmica Química (Brazil). Sabouraud agar was purchased from Kasvi (Brazil). $\mathrm{KH}_{2} \mathrm{PO}_{4}$ and $\mathrm{Mg}_{2} \mathrm{SO}_{4} \cdot 7 \mathrm{H}_{2} \mathrm{O}$ were purchase from Vetec (Brazil). 3,5Dinitrosalicylic acid (DNS), $p$-nitrophenyl- $\beta$-D-glucopyranoside (PNPG) and $p$-nitrophenyl- $\beta$-D-xylopiranoside (PNPX) were purchased from Sigma-Aldrich (Brazil).

\subsection{Raw material}

Raw SCB was provided by Usina Vale do Tijuco (Companhia Mineira de Açúcar e Álcool), Uberaba, Minas Gerais, Brazil. SCB was milled in an agricultural crusher to obtain particles of around $5 \mathrm{~mm}$ of size, washed with tap water to remove soluble compounds and then washed with distilled water. Afterwards, SCB was dried in an oven at $50{ }^{\circ} \mathrm{C}$ for $24 \mathrm{~h}$ and stored at room temperature prior to use.

\subsection{Alkaline pretreatment (APT) of sugarcane bagasse}

A $5 \mathrm{~L}$ round-bottomed flask was loaded with $100.0 \mathrm{~g}$ of SCB, on dryweight basis, and $2.5 \mathrm{~L}$ of an aqueous $2 \% \mathrm{NaOH}\left(\mathrm{w} \mathrm{v}^{-1}\right)$ solution. Then, a reflux condenser was attached to the flask, which was heated in a mantle at the solution boiling point $\left(\sim 100^{\circ} \mathrm{C}\right)$ for $4 \mathrm{~h}$ (Rodrigues et al., 2017). At the end of the APT, the pretreated SCB was defibered at $2800 \mathrm{rpm}$ and washed with distilled water until the $\mathrm{pH}$ of the filtrate was neutral. Then, pretreated SCB was dried in an oven at $50{ }^{\circ} \mathrm{C}$ for $12 \mathrm{~h}$ and stored prior to chemical characterization and used in the saccharification experiments.

\subsection{Scanning electron microscopy (SEM)}

Physical changes in the fiber structure of untreated SCB (U-SCB) and alkali pretreated SCB (APT-SCB) were examined by scanning electron microscopy (SEM) on a Hitachi microscope model TM 3000 (Japan). The solid samples were placed on aluminum stubs with carbon tapes, coated with gold and then analyzed at $15 \mathrm{kV}$.

\subsection{Chemical composition of untreated and pretreated sugarcane bagasse}

Samples of U-SCB and APT-SCB were chemically characterized for total Klason lignin (acid soluble and insoluble lignin) (TAPPI T13M-54), moisture content (TAPPI T264 OM-88) and ash content (TAPPI T211 OM-93). Holocellulose was obtained for quantification of the contents of cellulose and hemicelluloses by submitting an appropriate sample of SCB to the treatment with acid chlorite according to the method of Browning (1967). The $\alpha$-cellulose content, which is the cellulose fraction resistant to $17.5 \% \mathrm{NaOH}\left(\mathrm{w} \mathrm{w}^{-1}\right.$ ), was also determined (TAPPI T $203 \mathrm{~cm}-99$ ).

\subsection{Enzyme production by solid-state fermentation (SSF)}

The fungal strains Aspergillus fumigatus SCBM6 (thermophilic with optimum growth temperature of $45^{\circ} \mathrm{C}$ ) and Aspergillus niger SCBM1 (mesophilic with optimum growth temperature of $30^{\circ} \mathrm{C}$ ) were cultured by SSF for the production of enzymatic extracts. These fungal strains were obtained from the Microorganisms Collection of Laboratory of Environmental Microbiology, Federal University of Uberlândia (LAMICUFU), Brazil. They were previously isolated from SCB piles and identified at the specie level by sequencing the ribosomal DNA (Santos et al., 2015).

To prepare the pre-inoculum, the fungal strains were inoculated in $250 \mathrm{~mL}$ Erlenmeyer flasks containing $50 \mathrm{~mL}$ of sterilized Sabouraud inclined agar medium at $30^{\circ} \mathrm{C}$ for Aspergillus niger (SCBM1) and $45^{\circ} \mathrm{C}$ for Aspergillus fumigatus (SCBM6) for $72 \mathrm{~h}$. After $72 \mathrm{~h}, 20 \mathrm{~mL}$ of sterilized saline solution were added to the flasks and the media surfaces were scraped to obtain spores in suspension. The number of spores was calculated by counting in Neubauer's chamber in a biological optical microscope (BEL Photonics, model BIO3) and a volume equivalent to $10^{7}$ spores per gram of substrate was used to inoculate the samples in the fermentation flasks for growth and production of enzymatic extracts. Raw sugarcane bagasse and wheat bran (SCB and WB, 
respectively) were used as carbon sources in a raw SCB-to-WB ratio of $1: 1\left(\mathrm{w} \mathrm{w}^{-1}\right)$. Both substrates are lignocellulosic materials rich in nonstarch polysaccharides (41-60\%), being considered as a good culture medium for the development of fungi and enhancing the enzyme production by SSF (Maes et al., 2004). The chemical composition of WB was previously analyzed and presented $25.41 \%$ of cellulose, $26.45 \%$ of hemicelluloses, $25.77 \%$ of lignin and $18 \%$ of protein, indicating that this material has a lignocellulosic structure quite similar to the conventional SCB with an high content in polysaccharides, also being considered as a good substrate for the development of fungi and additional induction of (hemi)-cellulolytic enzymes.

To obtain the crude enzymatic extracts, the flasks were withdrawn every $24 \mathrm{~h}$ for Aspergillus fumigatus SCBM6 and every $48 \mathrm{~h}$ for Aspergillus niger SCBM1. For this, $50 \mathrm{~mL}$ of distilled water were added to the flasks and the flasks were manually shaken. Then, the flasks were subjected to an orbital shaking (Lucadema, model Luca 222,) at $150 \mathrm{rpm}$ for $1 \mathrm{~h}$. After that, the suspension was vacuum filtered and the filtrate was centrifuged for $30 \mathrm{~min}$ at $5000 \mathrm{rpm}$ and filtered again. The crude extracts obtained were collected and stored at $-20^{\circ} \mathrm{C}$. The enzymatic extracts produced by Aspergillus fumigatus SCBM6 and Aspergillus niger SCBM1 were referred to as AFE and ANE, respectively. All experiments were performed in triplicate.

\subsection{Enzymatic activities measurement}

The activity of xylanase was measured in reaction mixtures containing $30 \mu \mathrm{L}$ of crude enzymatic extract and $270 \mu \mathrm{L}$ of sodium acetate buffer $\left(0.1 \mathrm{~mol} \mathrm{~L}^{-1}\right.$ and $\left.\mathrm{pH} 5.0\right)$ containing $1 \%$ of xylan (Beechwood). The mixtures were incubated at $60{ }^{\circ} \mathrm{C}$ (AFE) and $40{ }^{\circ} \mathrm{C}$ (ANE) during $10 \mathrm{~min}$ and the TRS released was quantified by the method of 3,5-dinitrosalicylic acid (DNS) (Miller, 1959), using xylose standard curves (Rodrigues et al., 2017). One unit of enzymatic activity (U) was defined as the amount of enzyme required to release one $\mu$ mol of xylose per minute in the assay conditions.

The activity of $\beta$-glucosidase (cellobiase) was measured in reaction mixtures composed by $50 \mu \mathrm{L}$ of crude enzymatic extract, $250 \mu \mathrm{L}$ of sodium acetate buffer $\left(0.1 \mathrm{~mol} \mathrm{~L}^{-1}\right.$ and $\left.\mathrm{pH} 5.0\right)$ and $250 \mu \mathrm{L}$ of $p$-nitrophenyl- $\beta$-D-glucopyranoside (PNPG) $\left(4 \mathrm{mmol} \mathrm{L}^{-1}\right)$ at $60^{\circ} \mathrm{C}$ for AFE and $40^{\circ} \mathrm{C}$ for ANE for $10 \mathrm{~min}$ (Rodrigues et al., 2017). The reaction was stopped by the addition of $2.0 \mathrm{~mL}$ of aqueous $2.0 \mathrm{~mol} \mathrm{~L}^{-1}$ sodium carbonate $\left(\mathrm{Na}_{2} \mathrm{CO}_{3}\right)$. One unit of enzyme activity (U) was defined as the amount of enzyme required to release one $\mu \mathrm{mol}$ of $p$-nitrophenol per minute in the assay conditions. The activity of $\beta$-xylosidase was determined by the same procedure for $\beta$-glucosidase using $p$-nitrophenyl$\beta$-D-xylopiranoside (PNPX) as a substrate. One unit of enzyme activity (U) was defined as the amount of enzyme required to release one $\mu \mathrm{mol}$ of $p$-nitrophenol per minute in the assay conditions. A standard curve of p-nitrophenol was built for quantification (Santos et al., 2015). All experiments were performed in triplicate.

Cellulase activity on filter paper (FPase) was also assayed in a reaction mixture containing $1 \mathrm{~mL}$ of $0.05 \mathrm{~mol} \mathrm{~L}^{-1}$ citrate buffer, $\mathrm{pH} 4.8$, $0.5 \mathrm{~mL}$ of enzymatic extract and a filter paper tape of $1.0 \times 6.0 \mathrm{~cm}$. The reaction occurred for $1 \mathrm{~h}$ and was interrupted by the addition of $3 \mathrm{~mL}$ of DNS. The amount of glucose released was measured by spectrophotometry at $540 \mathrm{~nm}$ (Ghose, 1987).

\section{8. $\beta$-Glucosidase (CBU) characterization}

$\beta$-Glucosidase is a key enzyme in the enzymatic hydrolysis process. Then, the optimum conditions for the maximum $\beta$-glucosidase activity in the enzymatic extracts AFE and ANE were determined to keep the stability of the enzymes under the experimental hydrolysis conditions. Thus, optimum solution $\mathrm{pH}$, temperature, stability $\mathrm{pH}$ and thermostability in both extracts were evaluated.

The determination of the optimum solution $\mathrm{pH}$ was performed by incubating $50 \mu \mathrm{L}$ of crude enzymatic extract in $250 \mu \mathrm{L}$ of PNPG
( $4 \mathrm{mmol} \mathrm{L}^{-1}$ ) as a substrate, varying the solution $\mathrm{pH}$ from 3.5 to 8.0. The buffer solutions used were $0.1 \mathrm{~mol} \mathrm{~L}^{-1}$ sodium citrate (from 3.5 to 7.0) and $0.1 \mathrm{~mol} \mathrm{~L}^{-1}$ sodium phosphate (7.5 and 8.0). The enzymatic activity was measured at $60^{\circ} \mathrm{C}$ for AFE and $40^{\circ} \mathrm{C}$ for ANE. The hydrolysis reactions were stopped after $10 \mathrm{~min}$ by adding an aqueous $2 \mathrm{~mol} \mathrm{~L}^{-1} \mathrm{Na}_{2} \mathrm{CO}_{3}$ solution (Baffi et al., 2011). The optimum temperature for each enzymatic extract was evaluated by incubating $50 \mu \mathrm{L}$ of crude enzymatic extract under the same experimental conditions previously described at different temperatures from 30 to $80^{\circ} \mathrm{C}$. The activity assays were performed in $0.1 \mathrm{~mol} \mathrm{~L}^{-1}$ sodium citrate at optimum solution pH (Baffi et al., 2011).

The stability $\mathrm{pH}$ was measured by incubating the crude enzymatic extracts for $24 \mathrm{~h}$ at $25^{\circ} \mathrm{C}$, varying the solution $\mathrm{pH}$ from 3.5 to 8.0 using the same experimental procedures previously described. The residual $\beta$ glucosidase activity was determined under the respective optimum $\mathrm{pH}$ and temperature conditions (Baffi et al., 2011). To evaluate the thermostability of $\beta$-glucosidase, the crude enzymatic extracts were incubated in $0.1 \mathrm{~mol} \mathrm{~L}^{-1}$ sodium citrate buffer at optimum solution $\mathrm{pH}$ for $1 \mathrm{~h}$ at different temperatures (from 30 to $80^{\circ} \mathrm{C}$ ). Then, the enzymatic activity was measured at optimum $\mathrm{pH}$ and temperature. Afterwards, the thermostability was evaluated as a function of time for $2,4,8$ and $12 \mathrm{~h}$ at the optimum temperature previously determined and the residual enzymatic activity was quantified in both optimal conditions of $\mathrm{pH}$ and temperature (Baffi et al., 2011). All experiments were carried out in triplicate.

\subsection{Enzymatic saccharification of alkali pretreated sugarcane bagasse}

Before the beginning of saccharification, the pretreated SCB was rehydrated overnight in order to preserve the enzymatic hydrolysis yield. Enzymatic hydrolyses were carried out in $125 \mathrm{~mL}$ Erlenmeyer flasks with rubber stoppers in suspensions of $20.0 \mathrm{~mL}$ containing $5.0 \mathrm{~mL}$ of sodium acetate buffer $\left(0.05 \mathrm{~mol} \mathrm{~L}^{-1}\right.$ and $\left.\mathrm{pH} 5.0\right)$, different ratios between crude enzymatic extracts (AFE-to-ANE ratio), distilled water and different amounts of alkali pretreated SCB $\left(\mathrm{w} \mathrm{V}^{-1}\right)$. All flasks were incubated at different temperatures at $150 \mathrm{rpm}$ in an orbital shaker incubator (Lucadema, model Luca 222).

The amount of each crude enzymatic extract was calculated based on the amount of cellulose present in alkali pretreated SCB used in each hydrolysis experiment, in which $1 \mathrm{Ug}^{-1}$ of $\beta$-glucosidase $\left(1 \mathrm{CBU} \mathrm{g}^{-1}\right.$ of cellulose) of each crude enzymatic extract was added in each hydrolysis flask. A $2^{4}$ full design of experiments with independent variables time $(t, \mathrm{~h})$, temperature $\left(T,{ }^{\circ} \mathrm{C}\right)$, amount of APT-SCB $\left(\mathrm{w} \mathrm{v}^{-1}, \%\right)$ and AFE-to-ANE ratio (AFE:ANE, \%) was built. The dependent variables evaluated were concentration of total reducing sugars (TRS, $\mathrm{g} \mathrm{L}^{-1}$ ) and TRS yield ( $\mathrm{g}_{\mathrm{TRS}} \mathrm{g}_{\text {APT- }}^{-1}$ $\mathrm{SCB}_{\mathrm{B}}, \%$ ) and amount of monosaccharides from hemicelluloses (xylose and arabinose) (mg of sugars per gram of hemicelluloses) and cellulose (glucose and cellobiose) (mg of glucose or cellobiose per gram of cellulose) released. TRS yield (\%) was determined by DNS method (Miller, 1959). The factor levels and the independent variables are shown in Table 1.

\subsection{Analytical methods}

Hydrolysates from each enzymatic hydrolysis experiments were

Table 1

Independent variables and factor levels for the $2^{4}$ full design of experiments used for optimization of enzymatic hydrolysis of alkali pretreated sugarcane bagasse.

\begin{tabular}{llll}
\hline Variables & \multicolumn{2}{l}{ Levels } \\
\cline { 2 - 4 } & -1 & 0 & +1 \\
\hline Time (h) & 12 & 24 & 36 \\
Temperature $\left({ }^{\circ} \mathrm{C}\right)$ & 47 & 55 & 63 \\
APT-SCB concentration $\left(\mathrm{w} \mathrm{v}^{-1}, \%\right)$ & 2.2 & 5 & 7.8 \\
AFE:ANE ratio $\left(\mathrm{v} \mathrm{v}^{-1}, \%\right)$ & 25 & 50 & 75
\end{tabular}


Table 2

Chemical composition of untreated bagasse (U-SCB) and alkaline pretreated bagasse (APT-SCB).

\begin{tabular}{lll}
\hline Composition (wt.\%) & U-SCB & APT-SCB \\
\hline Moisture & 9.53 & 7.77 \\
Ash & 0.65 & 0.22 \\
Lignin & 26.14 & 14.90 \\
Cellulose & 54.36 & 75.04 \\
Hemicelluloses & 13.52 & 12.78 \\
\hline
\end{tabular}

filtered off and analyzed for TRS by DNS method from a standard glucose curve (Miller, 1959). The concentration of cellobiose and monosaccharides (glucose, xylose and arabinose) released by the enzymatic hydrolysis of APT-SCB was determined by ion-exchange chromatography in a Dionex ICS 5000 HPAEC-PAD chromatograph using a CarboPac PA1 column at $25^{\circ} \mathrm{C}$ (Pereira et al., 2015).

\subsection{Statistical analysis}

Statistical analyses were performed using the software Statistica 7.0 (Statsoft Inc.). Analysis of variance (ANOVA) was carried out with sum of squares of the residuals (SS residuals) for analyzing the experimental error at a significance level of 95\%. Each experiment of enzymatic hydrolysis was performed in duplicate. The most complex model linear/ quadratic main effects plus 3-ways was used to model the dependent variables (responses). An effect was considered statistically significant when the value of $p<0.05$.
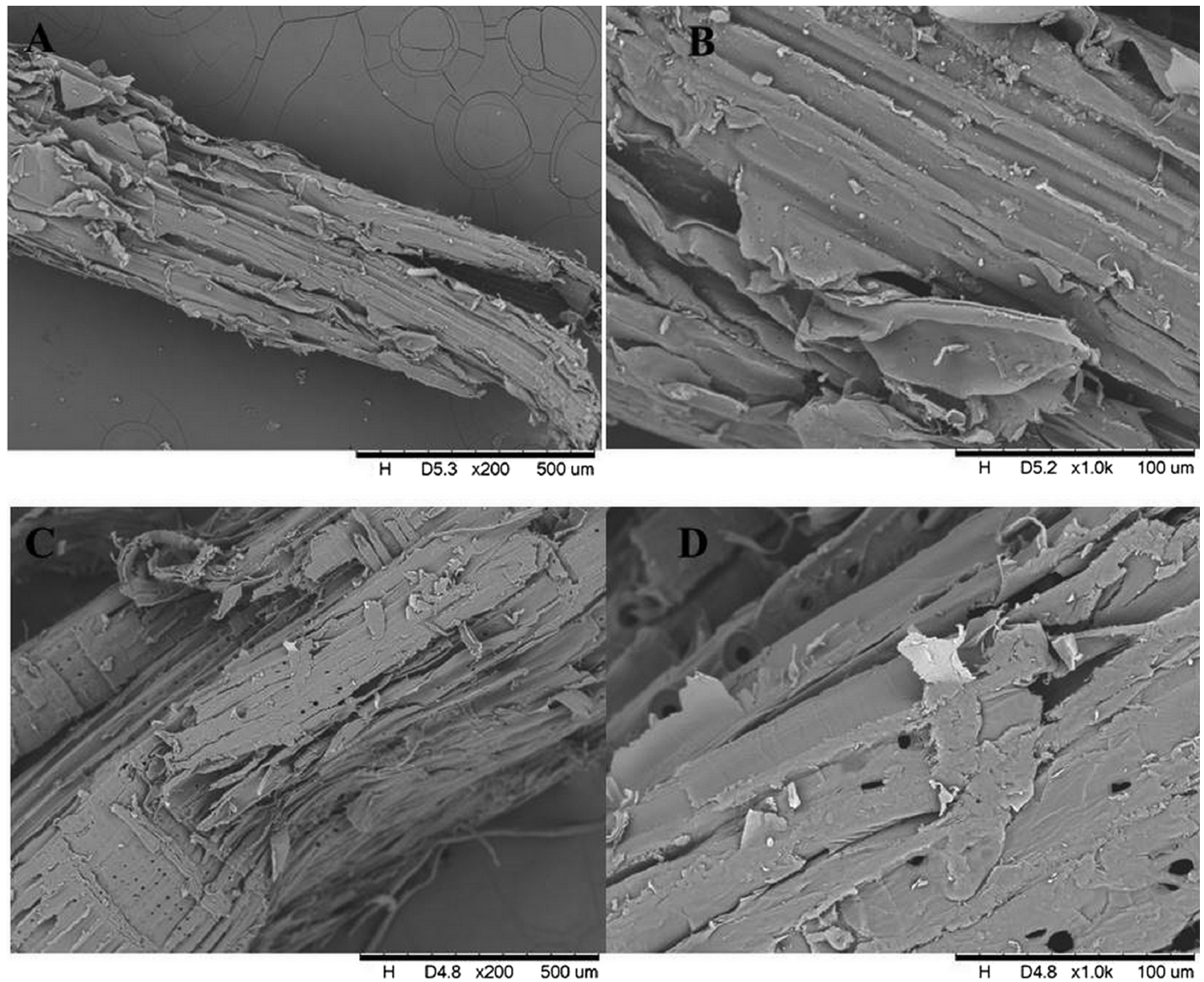

Fig. 1. Scanning electron microscopy micrographs of the untreated sugarcane bagasse (U-SCB) (a and b) and alkali pretreated sugarcane bagasse (APT-SCB) (c and d) at magnifications of $200 \times$ ( $a$ and $c$ ) and $1000 \times(b$ and $d)$. 


\subsection{Structural analysis of pretreated sugarcane bagasse by scanning electron microscopy (SEM)}

Fig. 1a-d shows SEM micrographs of U-SCB and APT-SCB with a magnification of $200 \times$ and $1000 \times$. The analyses of U-SCB and APTSCB by SEM showed that alkaline pretreatment changed the fiber structure of ATP-SCB in comparison to U-SCB. Fig. 1a and b shows that fibers of U-SCB are uniformly arranged and present some pores with smaller diameters. Fig. $1 \mathrm{c}$ and $\mathrm{d}$ shows that alkaline pretreatment promoted a disaggregation, disruption and degradation of the fibers and an increase in the porosity with the formation of cracks, which may have been caused by lignin removal. These changes probably make the polysaccharide fraction more accessible for enzymes (Rodrigues et al., 2017).

Rezende et al. (2011) evaluated the changes in the structure of sugarcane bagasse fibers pretreated with different concentrations of $\mathrm{NaOH}$ and reported that the use of higher $\mathrm{NaOH}$ concentrations in the pretreatment led to more severe structural changes in the fiber bundles with disaggregation and disruption of the fibers.

\subsection{Evaluation of enzyme production: $\beta$-glucosidase, $\beta$-xylosidase and xylanase}

The production of $\beta$-glucosidase, $\beta$-xylosidase and xylanase by the fungal strains Aspergillus fumigatus SCBM6 and Aspergillus niger SCBM1 was evaluated in function of time after SSF using raw SCB and WB as substrates. The time course of the enzymatic production by Aspergillus fumigatus SCBM6 and Aspergillus niger SCBM1 is shown in Fig. 2. As
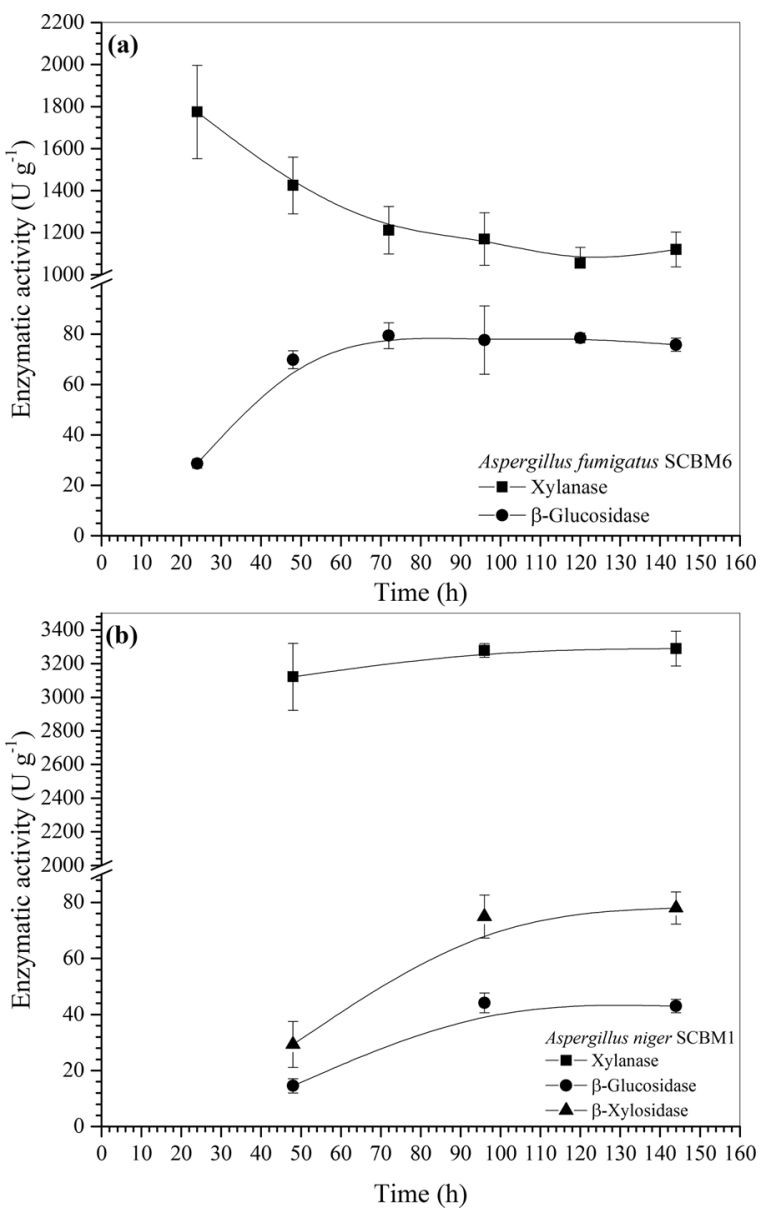

Fig. 2. Time course of enzyme production ( $\beta$-glucosidase, $\beta$-xylosidase and xylanase) by (a) A. fumigatus SCBM6 (at $45^{\circ} \mathrm{C}$ ) and (b) A. niger SCBM1 (at $30^{\circ} \mathrm{C}$ ) by SSF using raw SCB and WB as substrates $(1: 1, w / w)$. shown in Fig. 2, elevated enzymatic activities were produced by both fungal species. For $\beta$-glucosidase, the maximum production obtained by the growth of Aspergillus fumigatus SCBM6 (AFE extract) was $78.47 \mathrm{U} \mathrm{g}^{-1}$ after $120 \mathrm{~h}$ of SSF, whereas Aspergillus niger SCBM1 (ANE extract) produced $43.02 \mathrm{U} \mathrm{g}^{-1}$ in $144 \mathrm{~h}$. The enzyme $\beta$-xylosidase was only produced by Aspergillus niger SCBM1 (ANE extract) with a significant production $\left(78.00 \mathrm{Ug}^{-1}\right.$ in $\left.144 \mathrm{~h}\right)$. Xylanase was the enzyme with the highest production rate for both fungal species in SSF, i.e. AFE produced $1774.50 \mathrm{U} \mathrm{g}^{-1}$ in $24 \mathrm{~h}$ and ANE produced $3289.58 \mathrm{U} \mathrm{g}^{-1}$ in $144 \mathrm{~h}$. Other cellulases and hemicellulases were not detected at relevant concentrations.

The SSF plays a prominent role in the use of agroindustrial residues, since it allows the growth of microorganisms in these alternative substrates of lower cost, making possible the production of several microbial enzymes with an elevated yield and a lower cost in comparison to the most used culture media (Pereira et al., 2015; Rodrigues et al., 2017; Singhania et al., 2010). Aspergillus strains have been described in previous studies as good producers of extracellular enzymes, especially xylanases by SSF (Gomes et al., 2016; Santos et al., 2015). Moretti et al. (2012) reported a maximum activity of xylanase by Aspergillus fumigatus M.7.1 strain of $1040.0 \mathrm{U} \mathrm{g}^{-1}$ in $144 \mathrm{~h}$ of fermentation, using SCB and $\mathrm{WB}$ as substrates. As for $\beta$-glucosidase, the maximum activity reported by these authors was about $5 \mathrm{U} \mathrm{g}^{-1}$ in $192 \mathrm{~h}$. Bansal et al. (2012) also evaluated the production of $\beta$-glucosidase by Aspergillus niger NS-2 strain by SSF using raw SCB as a substrate. The maximum activity reported by these authors was $3 \mathrm{U} \mathrm{g}^{-1}$ in $96 \mathrm{~h}$ of incubation. Santos et al. (2015) also evaluated the production of $\beta$-glucosidase, $\beta$-xylosidase and xylanase by the Aspergillus niger SCBM3 strain using SCB and WB as substrates. They reported enzymatic activities of 54, 73 and $39 \mathrm{U} \mathrm{g}^{-1}$ after 240,144 and $48 \mathrm{~h}$ of SSF, respectively. Based on these comparisons, it can be concluded that both fungal strains evaluated in the present study were excellent producers of (hemi-)cellulolytic enzymes, demonstrating a superior production in comparison to those found in the other studies reported in the literature.

The filter paper activity (FPase) was quantified in the enzymatic extracts according the methodology proposed by Ghose (1987). However, the obtained activities were not significant with maximum activity around $11.83 \mathrm{FPU} / \mathrm{g}$ substrate in ANE extract after $96 \mathrm{~h}$ of SSF (data not shown).

\section{4. $\beta$-Glucosidase characterization}

The $\mathrm{pH}$ and the temperature are important process variables in the enzymatic hydrolysis process and may be determining factors for a good release of TRS in the end of the saccharification process. For example, a variation in the solution $\mathrm{pH}$ may influence the yield of fermentable sugars, as it causes a change in the net charges of the amino acid residues that compose the tridimensional structure of an enzyme, leading to protein denaturation and consequent loss of enzymatic activity (Nelson and Cox, 2012).

In order to improve the enzymatic hydrolysis efficiency, crude enzymatic extracts produced by SSF were characterized for optimum solution $\mathrm{pH}$ and temperature for $\beta$-glucosidase. In addition, the stability of $\beta$-glucosidase against different values of $\mathrm{pH}$ and temperature was also evaluated. For the $\beta$-glucosidase present in ANE extract, the optimum $\mathrm{pH}$ was 4.5 and in AFE extract was 5.0, as can be seen in Fig. 3a. These results suggest that both $\beta$-glucosidases present in ANE and AFE extracts are acidophilic in nature, presenting maximum activities in a $\mathrm{pH}$ range from 3.5 to 5.5 , as also reported in other characterization studies for $\beta$-glucosidases (Baffi et al., 2011; Santos et al., 2015).

The optimum temperature obtained for $\beta$-glucosidase present in ANE extract was $65^{\circ} \mathrm{C}$ and for ANE extract was $70{ }^{\circ} \mathrm{C}$, as shown in Fig. 3b. Regarding the stability of $\beta$-glucosidase at different $\mathrm{pH}$ values, both enzymatic extracts maintained a relatively constant residual activity between $\mathrm{pH}$ values from 3.5 to 7.0. At $\mathrm{pH}$ values higher than 7.0 the residual enzymatic activity was drastically reduced, as shown in 

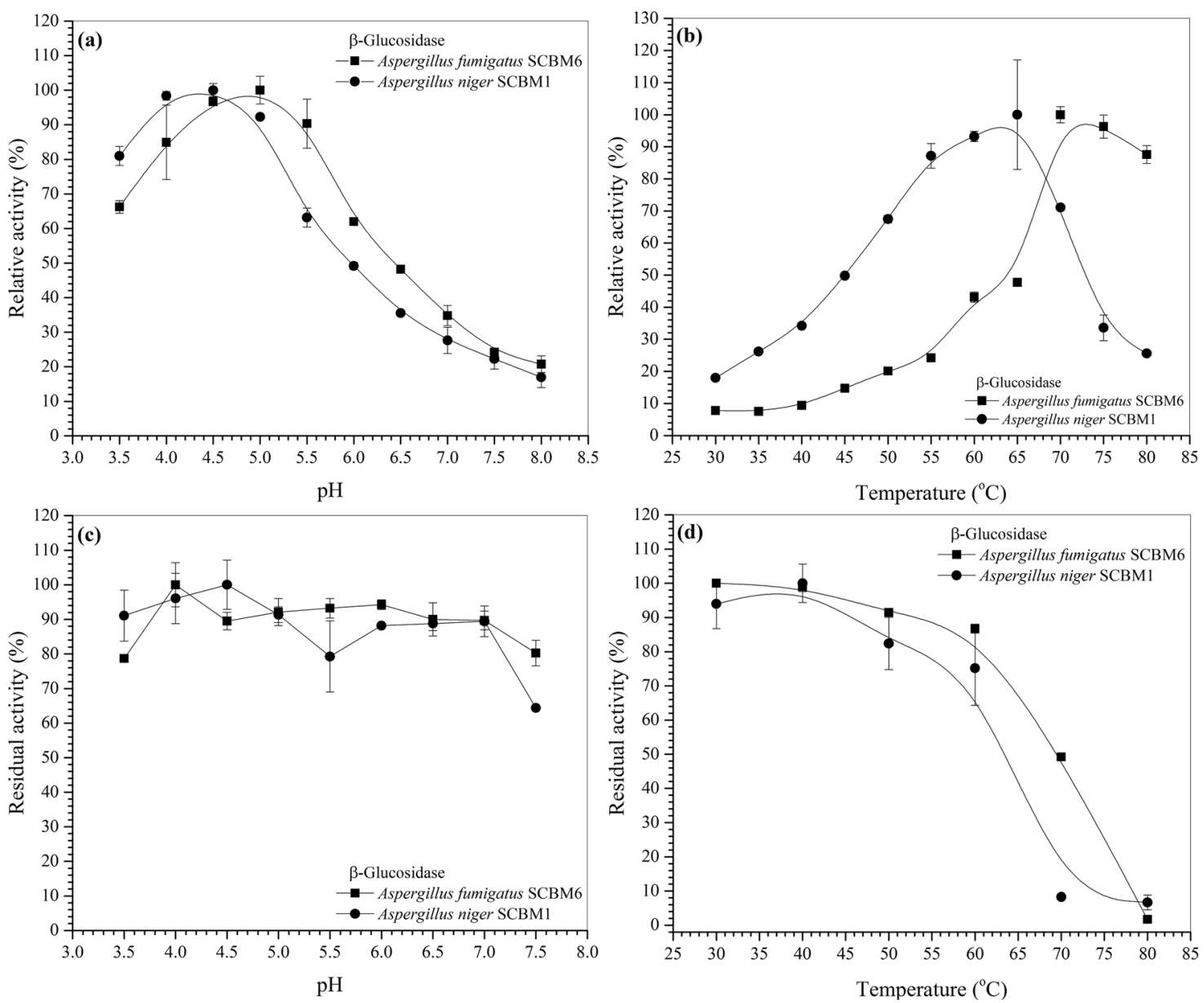

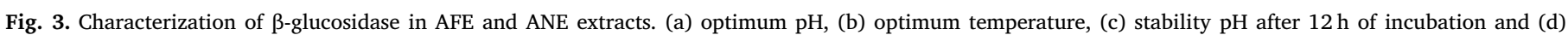
thermostability after $1 \mathrm{~h}$ of incubation.

Fig. 3c. As for thermostability, it was observed that after $1 \mathrm{~h}$ of incubation, a maximum residual activity between 80 and $90 \%$ remained in a temperature range from 30 to $50{ }^{\circ} \mathrm{C}$, as shown in Fig. 3d. These results corroborate with those reported by Pereira et al. (2016), who evaluated the optimum temperature, $\mathrm{pH}$ and stability temperature for different enzymes produced by Myceliophthora thermophila JCP-4. These authors reported an optimum $\mathrm{pH}$ of 5.5 with stability between $\mathrm{pH}$ values from 3.5 to 7.0 and thermostability in a temperature range from 35 to $55^{\circ} \mathrm{C}$. Most microbial enzymes present best performance at temperatures ranging from 30 to $70^{\circ} \mathrm{C}$, being that few enzymes resist to elevated temperatures for a long time (Baffi et al., 2011; Pereira et al., 2015). Thus, thermostability studies are important, mainly for application in industrial process where temperature changes may occur (Moretti et al., 2012). In the present study, residual $\beta$-glucosidase activity of both enzyme extracts considerably decreased at temperatures above $50{ }^{\circ} \mathrm{C}$, thereby indicating that in the hydrolysis processes a lower temperature should be used.

Subsequently, a second analysis was performed by setting the temperature at $50{ }^{\circ} \mathrm{C}$ and varying the time. In this analysis, the maximum residual activity was observed after incubation between 8 and $12 \mathrm{~h}$ for $\beta$-glucosidase obtained from both AFE and ANE extracts, as depicted in Fig. 4. Previous studies reported in the literature have shown that in the enzymatic hydrolysis process the highest glucose yield occurs in the first hours of saccharification, which is a period that $\beta$-glucosidase has maximum activity (Huang et al., 2016; Siqueira et al., 2013).

\subsection{Total reducing sugars yield (TRS)}

The enzymatic hydrolyses of APT-SCB were carried out using mixed enzymatic cocktails produced by Aspergillus fumigatus SCBM6 (AFE extract) and Aspergillus niger SCBM1 (ANE extract) in different AFE-toANE ratios to potentiate the synergistic action of the enzymes present in both crude extracts for depolymerization of polysaccharides of APTSCB.

The maximum concentration of TRS $\left(21.68 \mathrm{~g} \mathrm{~L}^{-1}\right)$ was obtained in the hydrolysis condition 16, i.e. $36 \mathrm{~h}, 47^{\circ} \mathrm{C}, 7.8 \%\left(\mathrm{w} \mathrm{v}^{-1}\right)$ of APT-SCB and AFE:ANE of 25:75 (\%), as presented in Table 3. The highest TRS yield per gram of APT-SCB (38.22\%) was obtained in the hydrolysis condition 4, i.e. $12 \mathrm{~h}, 47^{\circ} \mathrm{C}, 2.2 \%\left(\mathrm{w} \mathrm{v}^{-1}\right)$ of APT-SCB and AFE:ANE of 25:75 (\%). Slightly higher values TRS $\left(30.00 \mathrm{~g} \mathrm{~L}^{-1}\right)$ were obtained by Huang et al. (2015) after simultaneous saccharification and fermentation of sugarcane bagasse pretreated with peroxyacetic acid (PAA) in basic medium $(\mathrm{NaOH})$. However, these authors performed the enzymatic hydrolysis for a longer time $(96 \mathrm{~h})$ at $50{ }^{\circ} \mathrm{C}$ and used enzymatic extracts produced by Penicillium oxalicum EU2106. In another study, Huang et al. (2016) reported a concentration of TRS of $20.2 \mathrm{~g} \mathrm{~L}^{-1}$ after saccharification of sugarcane bagasse pretreated with sodium ethoxide $\left(\mathrm{CH}_{3} \mathrm{CH}_{2} \mathrm{ONa}\right.$ ), using a commercial enzyme cocktail (Celluclast $1.5 \mathrm{~L}$ and Novozym 188) under the hydrolysis conditions of $72 \mathrm{~h}, 45^{\circ} \mathrm{C}$ and $3 \%\left(\mathrm{w} \mathrm{v}^{-1}\right)$ of pretreated bagasse. Comparing the TRS concentrations and yields obtained in the present study with those reported in the literature, it can be concluded that the enzymatic hydrolysis performed in the present study was efficient with an appreciable release of TRS in a relatively shorter time. 


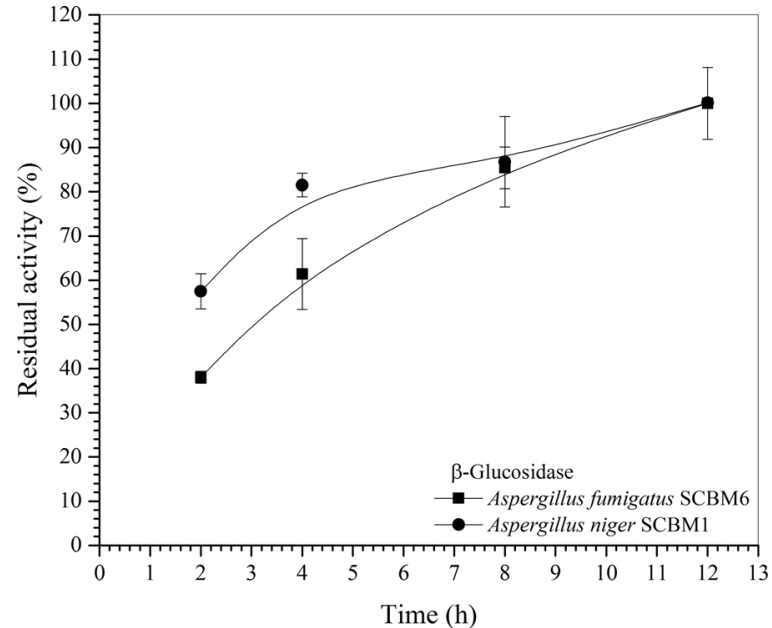

Fig. 4. Thermostability of $\beta$-glucosidase in ANE (Aspergillus niger) and AFE (Aspergillus fumigatus) extracts after incubation at $50^{\circ} \mathrm{C}$ in different periods of time.

The influence of the independent variables time, temperature, amount of APT-SCB and AFE-to-ANE ratio on the conversion of APTSCB polysaccharides into TRS was evaluated by the Pareto's chart and analysis of variance (ANOVA) with a significance level of $95 \%$ $(p=0.05)$. The analysis of variance showed that the model exhibited values of coefficient of determination $\left(R^{2}\right)$ and $R_{\text {adj }}^{2}$ higher than 0.99 , which indicates that the experimental data was well fitted by the proposed model. Regression model, in terms of uncoded variable levels for the response TRS yield, is a polynomial equation, as follows:

TRS yield $/(\%)=213.4510-4.8055 t-2.9797 T-9.628 A P T-S C B-$ 1.9464AFE:ANE + 0.0655t $\times T+0.6544 t \times A P T-$

$S C B+0.0268 t \times A F E: A N E+0.1048 T \times A P T-$

$S C B+0.0277 T \times A F E: A N E+0.0331 A P T-S C B \times A F E: A N E-$

$0.0085 t \times T \times A P T-S C B-0.0003 t \times T \times A F E: A N E-0.0018 t \times A P T-$

$S C B \times A F E: A N E+0.0001 T \times A P T-S C B \times A F E: A N E$

The variable temperature $(-37.4278)$ was the variable that presented the highest significant effect, being its effect potentiated for the production of TRS when applied at the lower level $\left(47^{\circ} \mathrm{C}\right)$. Similar behaviors were observed for time $(-12.8062)$ and AFE-to-ANE ratio
$(-27.9402)$, in which lower levels $(12 \mathrm{~h}$ and 25:75) also favored the production of TRS. As expected, the variable APT-SCB (5.6944) presented a positive significant effect on TRS yield, i.e. the production of TRS is favored when applied at the higher level (5.6944). Previous studies reported in the literature have shown that temperatures between 40 and $60{ }^{\circ} \mathrm{C}$ favor the release of TRS during saccharification, decreasing the chances of the release of inhibitors such as furan derivatives, 2-furfuraldehyde and 5-hydroxymethyl-2-furfuraldehyde (HMF), among others (Pereira et al., 2016; Rabelo et al., 2011). Similarly, other studies indicate that $65 \%$ of the sugars are released within the first $24 \mathrm{~h}$ of enzymatic hydrolysis (Gao et al., 2014; Rabelo et al., 2014). A similar profile was also observed in the present study when the interaction between two factors and three factors are analyzed. The interactions between $T \times$ AFE-to-ANE ratio (23.1024), $t \times A P T-S C B$ (18.1168) and $T \times t$ (4.3725) had a positive significant effect on TRS yield while the interaction between $T \times A P T-S C B(-11.6088), A P T$ $S C B \times A F E: A N E$ ratio $(-2.3955)$ and $t \times$ AFE:ANE ratio $(-2.0164)$ had a negative significant effect on TRS yield. In addition, the interaction between $t \times T \times A F E: A N E$ ratio $(-8.4551)$ and $t \times T \times A P T$ $S C B(-3.9616)$ also presented a negative significant effect on TRS yield. Pereira et al. (2016) also evaluated the influence of time on the enzymatic hydrolysis process using an enzymatic extract produced by Myceliophthora thermophila JCP1-4 and reported that 70\% of TRS released $\left(4.99 \mathrm{~g} \mathrm{~L}^{-1}\right)$ occurred within the first $8 \mathrm{~h}$ of enzymatic hydrolysis. These data corroborate with those obtained in the present study, and therefore, prove that the enzymatic hydrolysis is more efficient when performed in a shorter incubation period.

\subsection{Monosaccharides and cellobiose release}

The concentrations of the monosaccharides glucose, xylose and arabinose and the disaccharide cellobiose were quantified in the hydrolysates after enzymatic hydrolysis of APT-SCB in different experimental conditions as can be seen in Table 4 . The maximum glucose released per gram of cellulose $\left(20.18 \mathrm{mg} \mathrm{g}^{-1}\right)$ was obtained in experiment 10 , which was carried out for $12 \mathrm{~h}$ at $63^{\circ} \mathrm{C}$ with $2.2 \%\left(\mathrm{w} \mathrm{v}^{-1}\right)$ APT-SCB and AFE-to-ANE ratio of 25:75 (\%). For cellobiose, the best result was obtained in experiment 9 , i.e. $3.69 \mathrm{mg}_{\text {cellobiose }} \mathrm{g}_{\text {cellulose }}^{-1}$ Such release of cellobiose suggest that the depolymerization of cellulose was not complete, indicating the need to improve the hydrolysis conditions to increase the glucose yield. A possible explanation for these results is that only $1 \mathrm{Ug}^{-1}$ of $\beta$-glucosidase ( $1 \mathrm{CBU} \mathrm{g}_{\text {cellulose}}^{-1}$ ) of each crude

Table 3

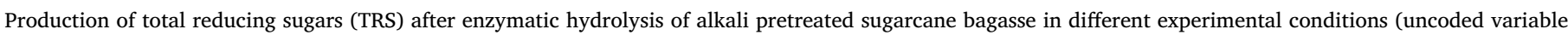
levels).

\begin{tabular}{|c|c|c|c|c|c|c|}
\hline Experiment & Time (h) & Temperature $\left({ }^{\circ} \mathrm{C}\right)$ & APT-SCB (\%) & $\mathrm{AFE}^{\mathrm{a}}$-to- $\mathrm{ANE}^{\mathrm{b}}$ ratio (\%) & $\operatorname{TRS}\left(\mathrm{g} \mathrm{L}^{-1}\right)^{\mathrm{c}}$ & TRS yield $^{\mathrm{d}}(\%)$ \\
\hline 1 & 36 & 47 & 2.2 & 25 & 2.41 & 14.66 \\
\hline 2 & 12 & 47 & 2.2 & 75 & 2.38 & 14.45 \\
\hline 3 & 36 & 63 & 2.2 & 25 & 0.91 & 5.52 \\
\hline 4 & 12 & 47 & 2.2 & 25 & 6.30 & 38.22 \\
\hline 5 & 36 & 63 & 7.8 & 75 & 1.72 & 2.94 \\
\hline 6 & 12 & 47 & 7.8 & 75 & 7.41 & 12.68 \\
\hline 7 & 12 & 63 & 7.8 & 75 & 3.97 & 6.79 \\
\hline 8 & 12 & 63 & 7.8 & 25 & 3.81 & 6.51 \\
\hline 9 & 36 & 63 & 7.8 & 25 & 4.85 & 8.29 \\
\hline 10 & 12 & 63 & 2.2 & 25 & 1.98 & 12.02 \\
\hline 11 & 36 & 47 & 2.2 & 75 & 0.54 & 3.29 \\
\hline 12 & 12 & 63 & 2.2 & 75 & 1.59 & 9.64 \\
\hline 13 & 12 & 47 & 7.8 & 25 & 17.73 & 30.31 \\
\hline 14 & 36 & 63 & 2.2 & 75 & 0.98 & 5.95 \\
\hline 15 & 36 & 47 & 7.8 & 75 & 9.19 & 15.70 \\
\hline 16 & 36 & 47 & 7.8 & 25 & 21.68 & 37.06 \\
\hline
\end{tabular}

\footnotetext{
a AFE: crude enzymatic extract from Aspergillus fumigatus SCBM6.

b ANE: crude enzymatic extract from Aspergillus niger SCBM1.

c TRS: total reducing sugars (each experiment was performed in duplicate and the value of TRS expressed as the average of two experiments).

d $\mathrm{g}_{\text {TRS }} / \mathrm{g}_{\text {APT-SCB }} \times 100$.
} 
Table 4

Cellobiose, glucose, xylose and arabinose release after each enzymatic hydrolysis of alkali pretreated sugarcane bagasse.

\begin{tabular}{|c|c|c|c|c|c|c|c|c|}
\hline \multirow[b]{2}{*}{ Experiment } & \multicolumn{4}{|l|}{ Variables } & \multicolumn{2}{|c|}{ Sugars from cellulose $\left(\mathrm{mg} \mathrm{g}^{-1}\right)$} & \multicolumn{2}{|c|}{ Sugars from hemicelluloses $\left(\mathrm{mg} \mathrm{g}^{-1}\right)$} \\
\hline & Time (h) & Temperature $\left({ }^{\circ} \mathrm{C}\right)$ & APT-SCB (\%) & AFE-to-ANE ratio (\%) & Cellobiose & Glucose & Arabinose & Xylose \\
\hline 1 & 36 & 47 & 2.2 & 25 & 1.95 & 4.46 & 0 & 88.43 \\
\hline 2 & 12 & 47 & 2.2 & 75 & 0.06 & 1.99 & 1.56 & 128.96 \\
\hline 3 & 36 & 63 & 2.2 & 25 & 0.04 & 0.30 & 0.06 & 39.49 \\
\hline 4 & 12 & 47 & 2.2 & 25 & 0.25 & 7.59 & 8.71 & 135.59 \\
\hline 5 & 36 & 63 & 7.8 & 75 & 0.02 & 0.09 & 0 & 23.34 \\
\hline 6 & 12 & 47 & 7.8 & 75 & 2.99 & 0.60 & 57.10 & 66.66 \\
\hline 7 & 12 & 63 & 7.8 & 75 & 0.60 & 0.07 & 58.01 & 62.69 \\
\hline 8 & 12 & 63 & 7.8 & 25 & 3.23 & 0.99 & 15.85 & 0 \\
\hline 9 & 36 & 63 & 7.8 & 25 & 3.69 & 0.68 & 3.14 & 1.44 \\
\hline 10 & 12 & 63 & 2.2 & 25 & 0.21 & 20.18 & 0 & 0.20 \\
\hline 11 & 36 & 47 & 2.2 & 75 & 0.00 & 1.00 & 0 & 0.33 \\
\hline 12 & 12 & 63 & 2.2 & 75 & 2.99 & 9.51 & 0 & 0.11 \\
\hline 13 & 12 & 47 & 7.8 & 25 & 1.02 & 1.27 & 0 & 47.42 \\
\hline 14 & 36 & 63 & 2.2 & 75 & 1.88 & 0.24 & 0 & 22.00 \\
\hline 15 & 36 & 47 & 7.8 & 75 & 2.44 & 4.43 & 0 & 1.13 \\
\hline 16 & 36 & 47 & 7.8 & 25 & 2.00 & 0 & 0 & 0 \\
\hline
\end{tabular}

enzymatic extract was used in the enzymatic hydrolysis, which may also justify the moderate release of glucose. For xylose, the experimental conditions used in experiment $4\left(12 \mathrm{~h}, 47^{\circ} \mathrm{C}\right.$ and $2.2 \% \mathrm{w} \mathrm{v}^{-1}$ of APT-SCB) and AFE-to-ANE ratio of 25:75 (\%) were the most interesting for the production of this sugar $\left(135.59 \mathrm{mg}_{\text {xylose }} \mathrm{g}_{\text {hemicelluloses }}^{-1}\right)$. The highest production of arabinose was obtained in experiments 6 and 7 ( 57.10 and $58.01 \mathrm{mg}_{\text {arabinose }} g_{\text {hemicelluloses }}^{-1}$, which was also performed for $12 \mathrm{~h}$.

It was also observed that both temperatures (47 and $63{ }^{\circ} \mathrm{C}$ ) and amounts of APT-SCB (2.2 and 7.8\%, $\mathrm{w} \mathrm{v}^{-1}$ ) had a positive impact on the release of sugars. A AFE-to-ANE ratio of 25:75 (extract produced by Aspergillus niger in a higher proportion than the extract produced by Aspergillus fumigatus) was also more efficient in the saccharification process. When analyzing the variable time, it is noticed that for the three monosaccharides the best result was obtained when the enzymatic hydrolyses were carried out for $12 \mathrm{~h}$.

Moretti et al. (2014) evaluated the pretreatment of SCB with microwave irradiation and its effect on enzymatic hydrolysis for $24 \mathrm{~h}$ at $55^{\circ} \mathrm{C}$ using an enzymatic extract of M. thermophila M.7.7 containing endoglucanase activities, $\beta$-glucosidase and xylanase of 47.0, 1.0 and $220.0 \mathrm{U} \mathrm{g}^{-1}$, respectively. They reported a release of sugars of $0.6 \mathrm{mg} \mathrm{g}^{-1}$ cellobiose, $23.4 \mathrm{mg} \mathrm{g}^{-1}$ glucose, $5.1 \mathrm{mg} \mathrm{g}^{-1}$ xylose and $2.4 \mathrm{mg} \mathrm{g}^{-1}$ arabinose. In the present study, an approximate release of $20.18 \mathrm{mg}_{\text {glucose }} \mathrm{g}_{\text {cellulose }}^{-1}$ was noticed. However, higher values for xylose $(135.59 \mathrm{mg})$, arabinose $(58.01 \mathrm{mg})$ and cellobiose $(3.69 \mathrm{mg})$ per gram of hemicelluloses and cellulose, respectively, were found in the present study. These results suggest that the enzymatic hydrolyses performed in the present study were more efficient for the depolymerization of the hemicellulose fraction with high concentration of xylose and arabinose in the hydrolysates. The high activity of xylanase and $\beta$-xylosidase present in the crude enzymatic extracts, mainly in the ANE extract of Aspergillus niger, used in the enzymatic hydrolyses of APT-SCB may justify the greater efficiency in the depolymerization of hemicellulose fraction. Another factor that may have contributed to the higher production of pentoses was the preservation of the hemicellulose fraction in the alkaline pretreatment of SCB (Table 2).

In addition, the enzyme load used in hydrolysis experiments ( $1 \mathrm{U} \mathrm{g}^{-1}$ of $\beta$-glucosidase from each crude enzymatic extract) in the present study was much lower than those ones used in other studies (An et al., 2017; Pereira et al., 2016; Rabelo et al., 2011, 2014), which reported higher saccharification yields when commercial enzyme cocktails were used. Thus, the use of a crude enzymatic extract not concentrated represents a good economic advantage of the proposed process in the present study.

The enzymatic extract used in the hydrolysis experiments, mainly rich in hemicellulases, was suitable for depolymerization of hemicellulose fraction and release of pentoses (xylose and arabinose). Pentoses can be used for the production of $2 \mathrm{G}$ ethanol by fermentation of C5 sugars (Arruda et al., 2017). Alternatively, pentoses can be also used to produce value-added chemicals or advanced biofuels, such as the production of butanol, which has a great potential as a biofuel (Mariano et al., 2013). In addition, xylose can be used for the production of xylitol, acetic acid and lactic acid as well as biodegradable plastics, resins, among others (Arruda et al., 2017; Pereira et al., 2016). Thus, it is suggested that the enzymatic extracts rich in hemicellulases, produced in the present study, could be used for saccharification of hemicellulose fraction followed by fermentation of pentoses without the drawbacks inherent to the physicochemical processes of hemicelluloses extraction such as acid hydrolysis, steam explosion and hydrothermal, which produces fermentation inhibitors such as furan derivatives and lignin fragments.

\section{Conclusions}

The two fungal species (Aspergillus fumigatus SCBM6 (AFE) and Aspergillus niger SCBM1 (ANE)) used in the present study showed to be good producers of hydrolytic enzymes, mainly hemicellulases, when fed with raw sugarcane bagasse and wheat bran as substrates. The enzymatic hydrolyses performed with mixed crude enzymatic extracts (AFE and ANE) presented good yields for total reducing sugars (TRS), high yields for pentoses (xylose and arabinose) and a reasonable glucose release. However, the amount of glucose released (20.18 $\mathrm{mg}_{\text {glucose }} \mathrm{g}_{\text {cellulose }}^{-1}$ ) was a satisfactory result considering the low amount of $\beta$-glucosidase $\left(1 \mathrm{U} \mathrm{g}^{-1}\right)$ used in the enzymatic hydrolysis experiments. Due to the high concentration of hemicellulases in crude enzymatic extracts, a more efficient depolymerization of the hemicelluloses fraction was noticed in comparison to cellulose fraction. From an overall point of view, the results obtained indicated that to increase the yield of fermentable sugars and the subsequent use of these sugars in the production of second-generation ethanol and value-added bioproducts, shorter times $(12 \mathrm{~h})$ and lower temperatures $\left(47^{\circ} \mathrm{C}\right)$ should be used in the enzymatic hydrolysis process.

\section{Acknowledgments}

The authors are grateful to Federal University of Uberlândia (UFU) and Minas Gerais State Research Funding Agency (FAPEMIG grant number APQ-01360-14) for their financial support. 


\section{References}

An, Y.-X., Zong, M.-H., Hu, S.-Q., Li, N., 2017. Effect of residual lignins present in cholinium ionic liquid-pretreated rice straw on the enzymatic hydrolysis of cellulose, Chem. Eng. Sci. 161, 48-56.

Arruda, P.V.D., Santos, J.C.D., Rodrigues, R.D.C.L.B., Silva, D.D.V.D., Yamakawa, C.K., Rocha, G.J.D.M., Júnior, J.N., Pradella, J.G.D.C., Rossell, C.E.V., Felipe, M.D.G.D.A., 2017. Scale up of xylitol production from sugarcane bagasse hemicellulosic hydrolysate by Candida guilliermondii FTI 20037. J. Ind. Eng. Chem. 47, 297-302.

Baêta, B.E.L., Lima, D.R.S., Adarme, O.F.H., Gurgel, L.V.A., Aquino, S.F.D., 2016. Optimization of sugarcane bagasse autohydrolysis for methane production from hemicellulose hydrolyzates in a biorefinery concept. Bioresour. Technol. 200, 137-146.

Badshah, M., Lam, D.M., Liu, J., Mattiasson, B., 2012. Use of an Automatic Methane Potential Test System for evaluating the biomethane potential of sugarcane bagasse after different treatments. Bioresour. Technol. 114, 262-269.

Baffi, M.A., Tobal, T., Henrique, J., Lago, G., Leite, R.S.R., Boscolo, M., Gomes, E., DaSilva, R., 2011. A novel $\beta$-glucosidase from Sporidiobolus pararoseus: characterization and application in winemaking. J. Food Sci. 76, C997-C1002.

Bansal, N., Tewari, R., Soni, R., Soni, S.K., 2012. Production of cellulases from Aspergillus niger NS-2 in solid state fermentation on agricultural and kitchen waste residues. Waste Manag. 32, 1341-1346.

Boonyuen, N., Manoch, L., Luangsa-ard, J.J., Piasai, O., Chamswarng, C., Chuaseeharonnachai, C., Ueapattanakit, J., Arnthong, J., Sri-indrasutdhi, V., 2014. Decomposition of sugarcane bagasse with lignocellulose-derived thermotolerant and thermoresistant Penicillia and Aspergilli. Int. Biodeterior. Biodegrad. 92, 86-100.

Brienzo, M., Fikizolo, S., Benjamin, Y., Tyhoda, L., Görgens, J., 2017. Influence of pretreatment severity on structural changes, lignin content and enzymatic hydrolysis of sugarcane bagasse samples. Renew. Energy 104, 271-280.

Browning, B.L., 1967. Methods on Wood Chemistry. Interscience Publishers, New York.

CONAB, 2017. Companhia Nacional de Abastecimento (CONAB). Observatório Agrícola. Acompanhamento da safra brasileira de cana-de-açúcar, segundo levantamento da safra 2017/2018. Brasília, Brazil, p. 57.

Canilha, L., Chandel, A.K., Suzane dos Santos Milessi, T., Antunes, F.A.F., Luiz da Costa Freitas, W., Felipe, M.D.G.A., da Silva, S.S., 2012. Bioconversion of sugarcane biomass into ethanol: an overview about composition, pretreatment methods, detoxification of hydrolysates, enzymatic saccharification, and ethanol fermentation. J. Biomed. Biotechnol. 15.

Chandra, R., Takeuchi, H., Hasegawa, T., 2012. Methane production from lignocellulosic agricultural crop wastes: a review in context to second generation of biofuel production. Renew. Sustain. Energy Rev. 16, 1462-1476.

Dougherty, M.J., Tran, H.M., Stavila, V., Knierim, B., George, A., Auer, M., Adams, P.D., Hadi, M.Z., 2014. Cellulosic biomass pretreatment and sugar yields as a function of biomass particle size. PLoS One 9, 1-5.

Gao, Y., Xu, J., Yuan, Z., Zhang, Y., Liu, Y., Liang, C., 2014. Optimization of fed-batch enzymatic hydrolysis from alkali-pretreated sugarcane bagasse for high-concentration sugar production. Bioresour. Technol. 167, 41-45.

Ghose, T.K., 1987. Measurement of cellulase activities. Pure Appl. Chem. 59, 257-268.

Gomes, A.F.S., dos Santos, B.S.L., Franciscon, E.G., Baffi, M.A., 2016. Substract and temperature effect on xylanase production by aspergillus fumigatus using low cost agricultural wastes $=$ Efeito da temperatura e do substrato na produção de xilanase por aspergillus fumigatus utilizando resíduos agroindustriais de baixo custo. Biosci. J. 32.

Guilherme, A.A., Dantas, P.V.F., Santos, E.S., Fernandes, F.A.N., Macedo, G.R., 2015. Evaluation of composition, characterization and enzymatic hydrolysis of pretreated sugar cane bagasse. Braz. J. Chem. Eng. 32, 23-33.

Huang, Y., Qin, X., Luo, X.-M., Nong, Q., Yang, Q., Zhang, Z., Gao, Y., Lv, F., Chen, Y., Yu, Z., Liu, J.-L., Feng, J.-X., 2015. Efficient enzymatic hydrolysis and simultaneous saccharification and fermentation of sugarcane bagasse pulp for ethanol production by cellulase from Penicillium oxalicum EU2106 and thermotolerant Saccharomyces cerevisiae ZM1-5. Biomass Bioenergy 77, 53-63.

Huang, Q., Yan, Q., Fu, J., Lv, X., Xiong, C., Lin, J., Liu, Z., 2016. Comparative study of different alcoholate pretreatments for enhanced enzymatic hydrolysis of sugarcane bagasse. Bioresour. Technol. 211, 464-471.

Karp, S.G., Woiciechowski, A.L., Soccol, V.T., Soccol, C.R., 2013. Pretreatment strategies for delignification of sugarcane bagasse: a review. Braz. Arch. Biol. Technol. 56, 679-689.

Khajeeram, S., Unrean, P., 2017. Techno-economic assessment of high-solid simultaneous saccharification and fermentation and economic impacts of yeast consortium and onsite enzyme production technologies. Energy 122, 194-203.

Kumar, P., Barrett, D.M., Delwiche, M.J., Stroeve, P., 2009. Methods for pretreatment of lignocellulosic biomass for efficient hydrolysis and biofuel production. Ind. Eng. Chem. Res. 48, 3713-3729.

Lin, H., Wang, B., Zhuang, R., Zhou, Q., Zhao, Y., 2011. Artificial construction and characterization of a fungal consortium that produces cellulolytic enzyme system with strong wheat straw saccharification. Bioresour. Technol. 102, 10569-10576.

Liu, W., Chen, W., Hou, Q., Zhang, J., Wang, B., 2017a. Surface lignin change pertaining to the integrated process of dilute acid pre-extraction and mechanical refining of poplar wood chips and its impact on enzymatic hydrolysis. Bioresour. Technol. 228, 125-132.
Liu, Y., Wang, J., Wolcott, M.P., 2017b. Size effects on acid bisulfite pretreatment effi ciency: multiple product yields in spent liquor and enzymatic digestibility of pretreated solids. ACS Sustain. Chem. Eng. 5, 5418-5423.

Maes, C., Vangeneugden, B., Delcour, J.A., 2004. Relative activity of two endoxylanases towards water-unextractable arabinoxylans in wheat bran. J. Cereal Sci. 39, 181-186.

Mariano, A.P., Dias, M.O.S., Junqueira, T.L., Cunha, M.P., Bonomi, A., Filho, R.M., 2013. Utilization of pentoses from sugarcane biomass: techno-economics of biogas vs. butanol production. Bioresour. Technol. 142, 390-399.

Miller, G.L., 1959. Use of dinitrosalicylic acid reagent tor determination of reducing sugar. Anal. Chem. 31, 426-428.

Modenbach, A.A., Nokes, S.E., 2012. The use of high-solids loadings in biomass pretreatment-a review. Biotechnol. Bioeng. 109, 1430-1442.

Mood, S.H., Golfeshan, A.H., Tabatabaei, M., Salehi Jouzani, G., Najafi, G.H., Gholami, M., Ardjmand, M., 2013. Lignocellulosic biomass to bioethanol, a comprehensive review with a focus on pretreatment. Renew. Sust. Energy Rev. 27, 77-93.

Moretti, M.M.S., Bocchini-Martins, D.A., Silva, R.D., Rodrigues, A., Sette, L.D., Gomes, E., 2012. Selection of thermophilic and thermotolerant fungi for the production of cellulases and xylanases under solid-state fermentation. Braz. J. Microbiol. 43 1062-1071.

Moretti, M.M.D.S., Bocchini-Martins, D.A., Nunes, C.D.C.C., Villena, M.A., Perrone, O.M., Silva, R.D., Boscolo, M., Gomes, E., 2014. Pretreatment of sugarcane bagasse with microwaves irradiation and its effects on the structure and on enzymatic hydrolysis. Appl. Energy 122, 189-195.

Murphy, L., Bohlin, C., Baumann, M.J., Olsen, S.N., Sørensen, T.H., Anderson, L., Borch, K., Westh, P., 2013. Product inhibition of five Hypocrea jecorina cellulases. Enzyme Microb. Technol. 52, 163-169.

Nelson, D.L., Cox, M.M., 2012. Lehninger Principles of Biochemistry, 6th ed. W.H Freeman, New York.

Oliveira, L.R.M., Nascimento, V.M., Gonçalves, A.R., Rocha, G.J.M., 2014. Combined process system for the production of bioethanol from sugarcane straw. Ind. Crops Prod. 58, 1-7.

Pallapolu, V.R., Lee, Y.Y., Garlock, R.J., Balan, V., Dale, B.E., Kim, Y., Mosier, N.S., Ladisch, M.R., Falls, M., Holtzapple, M.T., Sierra-Ramirez, R., Shi, J., Ebrik, M.A., Redmond, T., Yang, B., Wyman, C.E., Donohoe, B.S., Vinzant, T.B., Elander, R.T. Hames, B., Thomas, S., Warner, R.E., 2011. Effects of enzyme loading and $\beta$-glucosidase supplementation on enzymatic hydrolysis of switchgrass processed by leading pretreatment technologies. Bioresour. Technol. 102, 11115-11120.

Pereira, J.D.C., Marques, N.P., Rodrigues, A., Oliveira, T.B.D., Boscolo, M., da Silva, R., Gomes, E., Martins, D.A.B., 2015. Thermophilic fungi as new sources for production of cellulases and xylanases with potential use in sugarcane bagasse saccharification. J. Appl. Microbiol. 118, 928-939.

Pereira, J.D.C., Travaini, R., Marques, N.P., Bolado-Rodríguez, S., Martins, D.A.B., 2016. Saccharification of ozonated sugarcane bagasse using enzymes from Myceliophthora thermophila JCP 1-4 for sugars release and ethanol production. Bioresour. Technol. 204, 122-129.

Rabelo, S.C., Amezquita Fonseca, N.A., Andrade, R.R., Maciel Filho, R., Costa, A.C., 2011. Ethanol production from enzymatic hydrolysis of sugarcane bagasse pretreated with lime and alkaline hydrogen peroxide. Biomass Bioenergy 35, 2600-2607.

Rabelo, S.C., Andrade, R.R., Maciel Filho, R., Costa, A.C., 2014. Alkaline hydrogen peroxide pretreatment, enzymatic hydrolysis and fermentation of sugarcane bagasse to ethanol. Fuel 136, 349-357.

Rezende, C.A., de Lima, M.A., Maziero, P., deAzevedo, E.R., Garcia, W., Polikarpov, I., 2011. Chemical and morphological characterization of sugarcane bagasse submitted to a delignification process for enhanced enzymatic digestibility. Biotechnol. Biofuels 4, 1-19.

Rocha, G.J.M., Nascimento, V.M., Silva, V.F.N.d., Corso, D.L.S., Gonçalves, A.R., 2014 Contributing to the environmental sustainability of the second generation ethanol production: delignification of sugarcane bagasse with sodium hydroxide recycling. Ind. Crops Prod. 59, 63-68.

Rodrigues, P.D.O., dos Santos, B.V., Costa, L., Henrique, M.A., Pasquini, D., Baffi, M.A., 2017. Xylanase and $\beta$-glucosidase production by Aspergillus fumigatus using commercial and lignocellulosic substrates submitted to chemical pre-treatments. Ind. Crops Prod. 95, 453-459.

Santos, B.S.L.D., Gomes, A.F.S., Franciscon, E.G., Oliveira, J.M.D., Baffi, M.A., 2015 Thermotolerant and mesophylic fungi from sugarcane bagasse and their prospection for biomass-degrading enzyme production. Braz. J. Microbiol. 46, 903-910.

Singhania, R.R., Sukumaran, R.K., Patel, A.K., Larroche, C., Pandey, A., 2010. Advancement and comparative profiles in the production technologies using solidstate and submerged fermentation for microbial cellulases. Enzyme Microb. Technol. 46, 541-549.

Siqueira, G., Várnai, A., Ferraz, A., Milagres, A.M.F., 2013. Enhancement of cellulose hydrolysis in sugarcane bagasse by the selective removal of lignin with sodium chlorite. Appl. Energy 102, 399-402.

Watanabe, H., Tokuda, G., 2010. Cellulolytic systems in insects. Annu. Rev. Entomol. 55, 609-632.

Zhang, Y.-M., Lu, X.-B., Dan, H.-B., Sun, Y.-K., 2009. Screening and enzymatic study of a composite microbial system FH3. Braz. Arch. Biol. Technol. 52, 35-43.

Zhu, J., Wan, C., Li, Y., 2010. Enhanced solid-state anaerobic digestion of corn stover by alkaline pretreatment. Bioresour. Technol. 101, 7523-7528. 